Original Research Paper

\title{
An Improved Speed-Density Relationship Model for Pedestrian Flow
}

\author{
${ }^{1}$ Luthful Alahi Kawsar, ${ }^{2}$ Noraida Abdul Ghani, ${ }^{3}$ Anton Abdulbasah Kamil and ${ }^{4}$ Adli Mustafa \\ ${ }^{I}$ Department of Statistics, Shahjalal University of Science and Technology, Sylhet, Bangladesh \\ ${ }^{2}$ School of Distance Education, Universiti Sains Malaysia, Penang, Malaysia \\ ${ }^{3}$ Telkom Engineering School, Telkom University, Bandung, Indonesia \\ ${ }^{4}$ School of Mathematical Sciences, Universiti Sains Malaysia, Penang, Malaysia
}

\author{
Article history \\ Received: 21-06-2016 \\ Revised: 22-08-2016 \\ Accepted: 28-01-2017 \\ Corresponding Author: \\ Luthful Alahi Kawsar \\ Department of Statistics, \\ Shahjalal University of Science \\ and Technology, Sylhet, \\ Bangladesh \\ Email: lakawsar@yahoo.com
}

\begin{abstract}
The speed-density relationship performs as a basis to realize the behavior of a complex system such as vehicular or pedestrian traffic flow. Based on the speed-density relationship, the relationships between other pedestrian characteristics such as speed-flow, flow-density and speedpedestrian module could be derived. Compared to vehicular flow, very little research has been done to develop a general model to describe pedestrian speed-density relationship. The widely used exponential speeddensity models, the Underwood model and the Drake model show that the maximum flow is obtained at jam density, which is illogical because at jam density the movement is very limited and the speed will be at its minimum level. In this study, we propose an improved deterministic speed-density model for pedestrian flow which is an important contribution in the field of pedestrian studies. The proposed model shows that the maximum flow occurs at a density which is less than the jam density and thus, overcoming the limitations of the existing models. The validity of the model is empirically verified by primary and secondary datasets. The results showed that the proposed model can describe the speed-density relationship for all the datasets that were collected for different scenarios such as indoor and outdoor facilities. This model can be used as a general speed-density relationship.
\end{abstract}

Keywords: Pedestrian, Walking Speed, Density, Flow, Indoor Facility, Outdoor Facility

\section{Introduction}

The three basic parameters that fully characterize pedestrian movement are flow, speed and density. The speed-density relationship performs as a base to realize the behavior of a complex system such as vehicular or pedestrian traffic flow. Pedestrian walking speed is mostly affected by the density; however, there are also some other personal and locational factors which also affect the walking speed (Rahman et al., 2012). Therefore, the speed density relationship model developed for vehicular flow is not appropriate to describe the pedestrian flow. The fundamental speeddensity relationship of pedestrian traffic flow is spotlighted in this study. Based on the speed-density relationship, the relationships between other pedestrian characteristics such as speed-flow, flow-density and speed-pedestrian module could be derived.

Pedestrian traffic flow studies can be divided into two categories: The microscopic approach and the macroscopic approach (May, 1990). Microscopic approach involves individual units with characteristics such as individual speed and individual interaction. The drawback to microscopic approach is that it involves complex, non-analytical mathematical models which require difficult and expensive simulation to solve.

Macroscopic models consider pedestrian behaviour in a continuum approach, where pedestrian movements are treated as a fluid. The drawback of this modelling is pedestrians tend to interact among 
themselves and with obstacles in their model area, which is not captured by the macroscopic models (Kachroo et al., 2008).

Deterministic speed-density models express a common system response, that is, for a specified density there exists a consequent speed from a deterministic rule. Greenshields et al. (1935) have proposed a very simple linear relationship between speed and density for vehicular traffic flows. Later, many researchers have devoted their study to improve this over-simplified relationship. Among them the well-known deterministic speed-density models for vehicular traffic flows are the Greenberg's Model (Greenberg, 1959), the Underwood Model (Underwood, 1960), the Drake Model (Drake et al., 1967), the Pipes-Munjal Generalized Model (Pipes, 1967) and the Drew Model (Drew, 1968).

These speed-density relationship models for vehicular flow are often used for studying pedestrian flow (Lam et al., 1995; Shende et al., 2007). However, pedestrian flow is more complex and is different from that of vehicular. It is influenced also by some other personal and locational factors (Rahman et al., 2012). Thus, the goal of this paper is to propose an improved deterministic speed-density model based on empirical data. The validity of the model is empirically verified by primary data collected from a hall room type facility during egress and also by different secondary datasets that are available online (Pedestrian data: http://www.ped-net.org/index.php?id=20\&ID=231).

The rest of the paper is organized in the following manner. Next section gives an overview of pedestrian speed-density relationships found in literature. An improvement of the speed-density model for pedestrian flow is proposed in the subsequent section. The details of the data collection procedure and the description of the secondary datasets are then presented followed by an empirical validation of the proposed model to ensure that it replicates the pedestrian speed-density relationship for the different scenarios. Finally, the last section presents the conclusions.

\section{Review of Pedestrian Flow Characteristics}

Pedestrian traffic flow characteristics studies mainly focus on deriving model equations for relationships between speed, flow and density. Pedestrian traffic flow was first studied by the Institute of Architecture of the Russian Academy of Arts (VAKH) in 1937 (Predtechenskii and Milinskii, 1978). The study has established the inverse relationship between the speed of pedestrian flow and density. However, the specific quantitative results obtained are unreliable because of the relatively small number of actual observations and other inadequacies. The well-known relation in traffic flow theory: $q=v^{*} k$

where, $q=$ flow, $v=$ speed and $k=$ density, has been observationally verified by a study conducted between 1946 and 1948 by the Central Scientific Research Institute of the Russian Fire Protection Service (VNIPO) (Predtechenskii and Milinskii, 1978). They have also introduced the graphical approach of studying pedestrian traffic flow, in terms of time-space diagrams.

The relationships among flow, speed and density have also been studied by a number of other researchers, namely, Hankin and Wright (1958) on the passengers in London subways and on British school boys, Oeding (1963) on mixed traffic (e.g., shoppers, commuters, sports spectators), Predtechenskii (1966) on mixed mass within a relatively limited area, Older (1968) on shoppers, Navin and Wheeler (1969) on students and Fruin (1971a) on commuters. These studies mainly focused on the pedestrian flow on selected facilities which depend upon the socioeconomic situations of the country being studied. Some of these studies have considered unidirectional and some have considered bidirectional or mixed pedestrian flows. In all these studies, except those by Hankin and Wright (1958) and Predtechenskii (1966), the relationship between speed and density is specified as linear. However, linear speeddensity relationship is not appropriate for both vehicular (HRB, 1965) and pedestrian flows (Pushkarev and Zupan, 1975). On the basis of a study conducted in 1966, Russian Engineering construction Institute (MISI) specified a polynomial relationship between pedestrian speed and density for horizontal movement under normal condition (Predtechenskii and Milinskii, 1978).

A detailed statistical study of different hypotheses regarding the pattern of the speed-density relationship for vehicular flow has been conducted by Drake et al. (1967). The results indicate that there are very little differences among these relationship patterns. Unfortunately, no such detailed investigation has been performed for pedestrian flows.

On the basis of the level of density, Henderson (1971, 1974), Henderson and Lyons (1972) and Henderson and Jenkins (1974) have divided pedestrian flow into loosely packed phase and densely packed phase and modelled it using the kinetic theory of gases. They measured the speeds of school children, university students and sidewalk pedestrians, for three different modes such as standing still, walking and running. It shows that the statistical distribution of speed approximately follow Maxwell-Boltzmann statistics in two dimensions. Burns and Lykoudis (1973) also have conducted a similar study of speed measurements of pedestrians walking alone, in pairs and in groups of three and suggested that pedestrian speed at low densities follow Maxwell-Boltzmann statistics in two dimensions. 
Based Tregenza's (1976) study, Yuhaski and Smith (1989) showed that linear and exponential models are very effective to present the relationship between the walking speed of a pedestrian and the crowd density.

The relationships between flow and pedestrian density have similar patterns for uni-directional, bi- directional and multi-directional flows (Fruin, 1971a). Thus, during evacuation, uni-directional flow can be used to present the bi-directional and multi-directional flows. $C$, is:

According to Tregenza (1976), the walkway capacity,

$$
C=5 L W
$$

where, $L$ and $W$ are the length and width of the walkway in meters.

Yuhaski and Smith (1989) developed the following linear and exponential models for uni-directional walking speed:

$v_{n}=\frac{A}{C}(C+1-n)$

$v_{n}=A \exp \left[-\left(\frac{n-1}{\beta}\right)^{\gamma}\right]$

where:

$$
\begin{aligned}
& \gamma=\ln \left[\frac{\ln \left(v_{a} / A\right)}{\ln \left(v_{b} / A\right)}\right] / \ln \left(\frac{a-1}{b-1}\right) \\
& \beta=\frac{a-1}{\left[\ln \left(A / v_{a}\right)\right]^{1 / \gamma}}=\frac{b-1}{\left[\ln \left(A / v_{b}\right)\right]^{1 / \gamma}}
\end{aligned}
$$

Where:

$$
\begin{aligned}
\gamma, \beta= & \begin{array}{l}
\text { Shape and scale parameters for the } \\
\text { exponential model }
\end{array} \\
v_{n}= & \text { Average walking speed for } n \text { occupants in a } \\
& \text { walkway } \\
v_{a}= & \text { Average walking speed when crowd density is } \\
& 2 \text { ped } / \mathrm{m}^{2} \\
v_{b}= & \text { Average walking speed when crowd density is } \\
& 4 \text { ped } / \mathrm{m}^{2} \\
A= & \text { Average walking speed of a lone occupant } \\
n= & \text { number of occupants in a walkway } \\
a= & 2 L \mathrm{~W} \\
b= & 4 L W
\end{aligned}
$$

In this study, $v_{a}, v_{b}$ and $A$ are assumed to have values of $0.64,0.25$ and $1.5 \mathrm{~m} \mathrm{sec}^{-1}$, respectively.

The linear model allows for pedestrian speed to be zero. However, pedestrian speed cannot be zero since they are able to manage a forward movement at high densities (Castle, 2007). The linear relationship for pedestrian flow is also opposed by Pushkarev and Zupan (1975). The exponential walking speed model represents the pedestrian speed-density relationship for walkways of an indoor facility. The shape and scale parameters are calculated by approximating three representative points from the six curves presented by Tregenza (1976). The assumptions of the values of $v_{a}, v_{b}$ and $A$ force the estimated curve to go through these points. Therefore, this model can describe the speed-density relationship only for some specific datasets.

Tanaboriboon et al. (1986) have showed that the walking speed of the pedestrians of Singapore is slower than that of Western countries. Tanaboriboon and Guyano (1991) also have found different walking speeds for pedestrians of Asian and Western countries. Morrall et al. (1991) have presented an extensive review of Asian pedestrian characteristics and compared the results with that of Canadian cities.

Based on a study on a particular site, Virkler and Elayadath (1994) have recommended that a multi-regime (probably 2-regime) model is a better portrayal of a pedestrian flow than the linear model. Lam and Cheung (2000) have found a higher free-flow and mean walking speed for outdoor walkways compared to indoor walkways.

Sarkar and Janardan (2001) have found that the rate of decrease of speed with density for Indian pedestrians is similar to the studies conducted by Older (1968) and Fruin (1971b). Considering the logarithmic relationships among pedestrian density, speed and flow, Fang et al. (2003) have presented a microscopic speed-density function for normal crowd flow. However, the function is unable to describe the relationship for a free flow or a high congested situation.

Lee (2005) has formulated separate two-regime models for upward and downward directions on stairways and escalators. For both the cases, he has found a linear relationship for the speed-density and quadratic relationships for flow-speed and flow-density.

Al-Azzawi and Raeside (2007) have collected video data on pedestrian flows and speeds and a variety of other variable from the sidewalks, which are representative of the different levels of service. They have derived a logarithmic equation for speed, flow and density relationships. However, the model is not appropriate because based on the physical relation $q=$ $v^{*} k$, speed is proportional to a positive power of density rather than being a decreasing function of density.

Jia et al. (2009) have conducted a data collection survey of pedestrian flow in the passenger transport terminal in Xizhimen underground station in China. They have derived a quadratic equation for pedestrian flow-density relationship; a multi-regime model for the flow-space relationship; and a single linear equation for speed-density relationship.

Chattaraj et al., (2009) have compared the speeddensity relationships of Indian and German pedestrians. 
They have found significant differences between the two pedestrian groups and suggested that cultural differences could have been the cause of such differences.

Utilizing the existing Level of Service (LOS) thresholds for pedestrian flow at signalized crosswalks, Alhajyaseen and Nakamura (2010) have proposed the required crosswalk widths for various pedestrian demand combinations.

Laxman et al. (2010) have studied pedestrian characteristics at four crowded locations in north India in mixed traffic condition. They have showed that the characteristics of the location and pedestrian themselves have their effect on the pedestrian flow characteristics. At all four locations the speed-density relationship is linear. The flow-density and flow-speed relationships are quadratic. A polynomial relationship is found between pedestrian flow and area module.

Alhajyaseen et al. (2011) have studied the effects of various pedestrian age groups (middle-age, elderly and pupils) on pedestrian flow characteristics and the capacity of signalized crosswalks for bidirectional flow. They have concluded that elderly pedestrians might cause a significant reduction in capacity up to $30 \%$.

Using the mixed factorial design, Rahman et al. (2012) have showed that different personal and locational factors have significant effect on pedestrian walking speed. Yao et al. (2012) have studied and analyzed the behavioural characteristics of pedestrian crowd for weaving and without weaving flow in a transport terminal in Beijing, China. They have showed linear speed-density graphs and quadratic flow-density and flow-speed graphs; however, no model is derived from the obtained graphs.

Rastogi et al. (2013) have studied pedestrian flow characteristics for 19 locations in five cities of India. They have showed that speed-density, flow-density and flow-area module follow exponential relationships, while the flow-speed equation follows a logarithmic relationship. At very low density, the behaviour of pedestrians are similar irrespective of the type of facility, however, behaviour is different at higher densities. They have observed different flow characteristics compared to those observed in the USA, UK, China and Southeast Asia, indicating a cultural effect.

Kawsar et al. (2014) have studied the empirical relationships between different pedestrian characteristics. They have showed that these relationships are different for indoor and outdoor facilities.

Gupta and Pundir (2015) have extensively reviewed the literature for various existing studies on pedestrian flow characteristics under different traffic situations. These studies focus on the important fundamental parameters of pedestrian flow. These parameters are pedestrian speed, density and flow.

\section{Improved Speed-Density Relationship Model for Pedestrian Flow}

To find an appropriate model for the speed-density relationship, primary data and various sets of secondary data have been examined in this study. The graphs of the secondary datasets show that the relationship pattern between speed and density is more likely to be exponential. Developed for vehicular flow, the Underwood model (Underwood, 1960) and the Drake model (Drake et al., 1967) are the two widely used exponential speed-density model for pedestrian flow and are given below:

$$
\begin{aligned}
& \text { Underwood model }: v=v^{f} \cdot \exp \left(-\frac{k}{k_{j}}\right) \\
& \text { Drake Model }: v=v^{f} \cdot \exp \left[-\frac{1}{2}\left(\frac{k}{k_{j}}\right)^{2}\right]
\end{aligned}
$$

where, $v$ is the speed, $v^{f}$ is the free flow speed, $k$ is the traffic density and $k_{j}$ is the jam density.

The Underwood model is unable to forecast speeds for congested densities, which is considered as a main drawback of the model (Wang, 2010). The Drake model, on the other hand, overestimates the free-flow region but underestimate the congested region (Wang, 2010). Figure 1 shows the flow-density relationships for the Underwood and Drake models.

The plot of flow against density for these two models show that the maximum flow is obtained at jam density, which is illogical because at jam density the movement is very limited and the speed will be at its minimum level. Since flow is the product of speed and density, at maximum density the flow should be at its minimum level, too.

Motivated by these exponential speed-density relationships and examining the pedestrian speeddensity relationship patterns for several secondary datasets, an improved speed-density model for pedestrian flow is proposed as:

$v=v^{f} \cdot \exp \left(-C_{d} \cdot \tilde{k}\right)$

where, $v$ is the speed, $v^{f}$ is the free flow speed of pedestrians, $\tilde{k}$ is the standardized density, i.e.:

$$
\frac{\text { Observed density }(k)}{\text { Jam density }\left(k_{j}\right)}
$$

where, $k$ is the pedestrian density and $k_{j}$ is the jam density. The value of $\tilde{k}$ lies between 0 and 1 . 


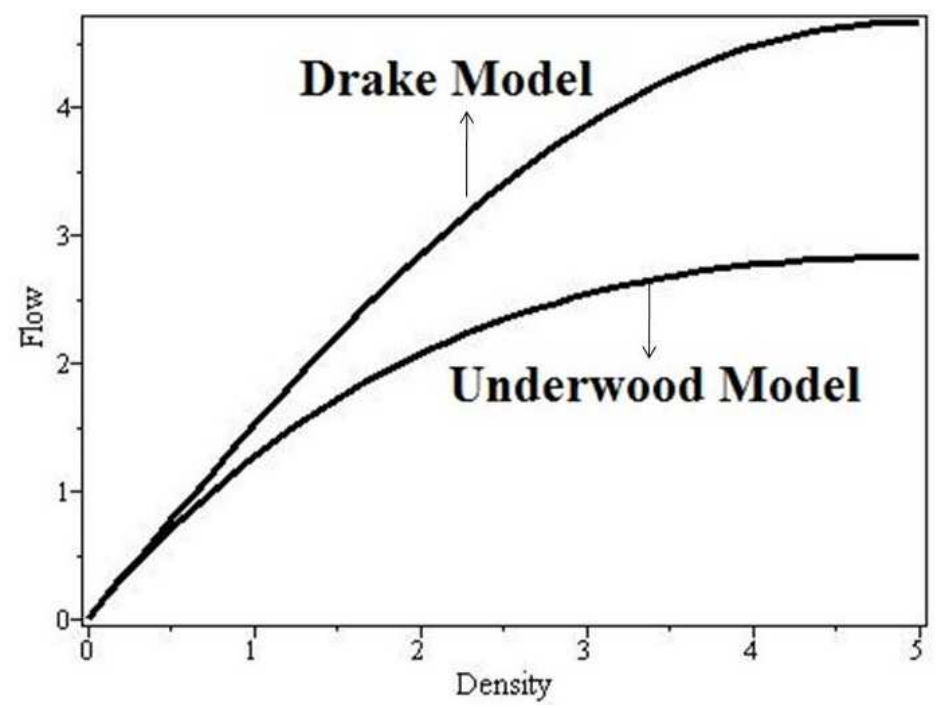

Fig. 1. Flow-density relationships for Underwood and Drake model

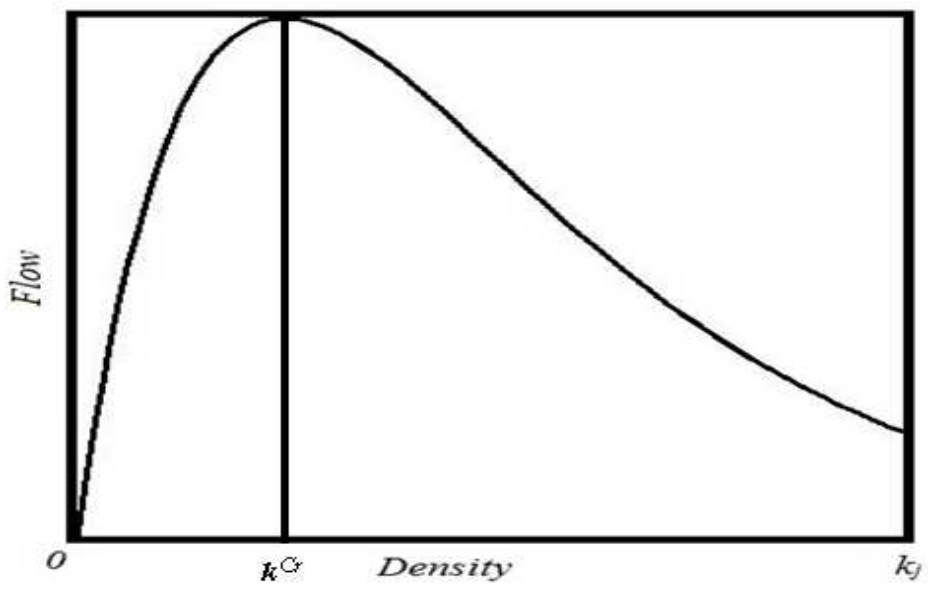

Fig. 2. Flow-density relationships for proposed model

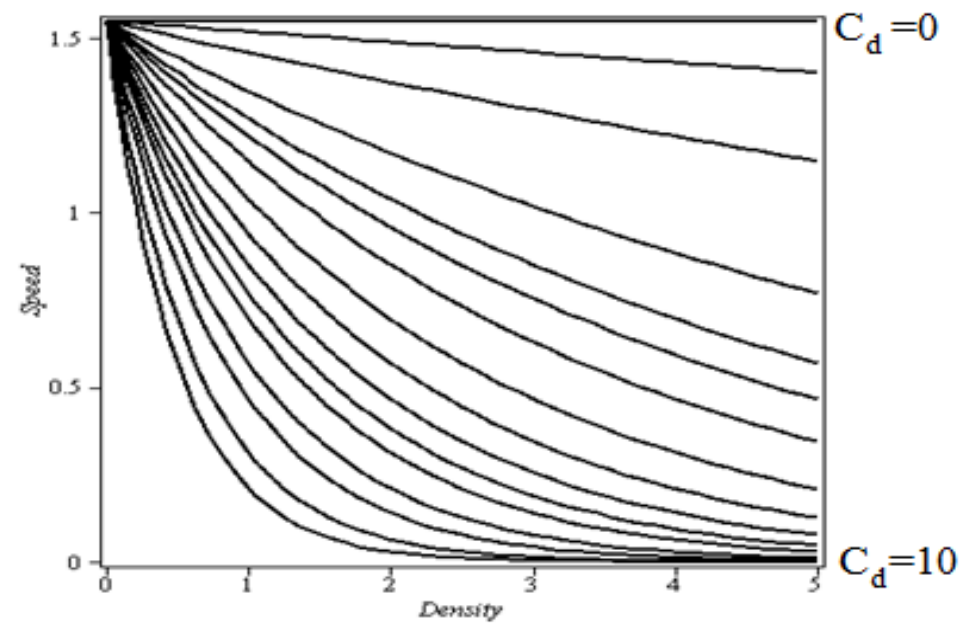

Fig. 3. Speed-density relationship for different values of $C_{d}, 0<C_{d} \leq 10$ 


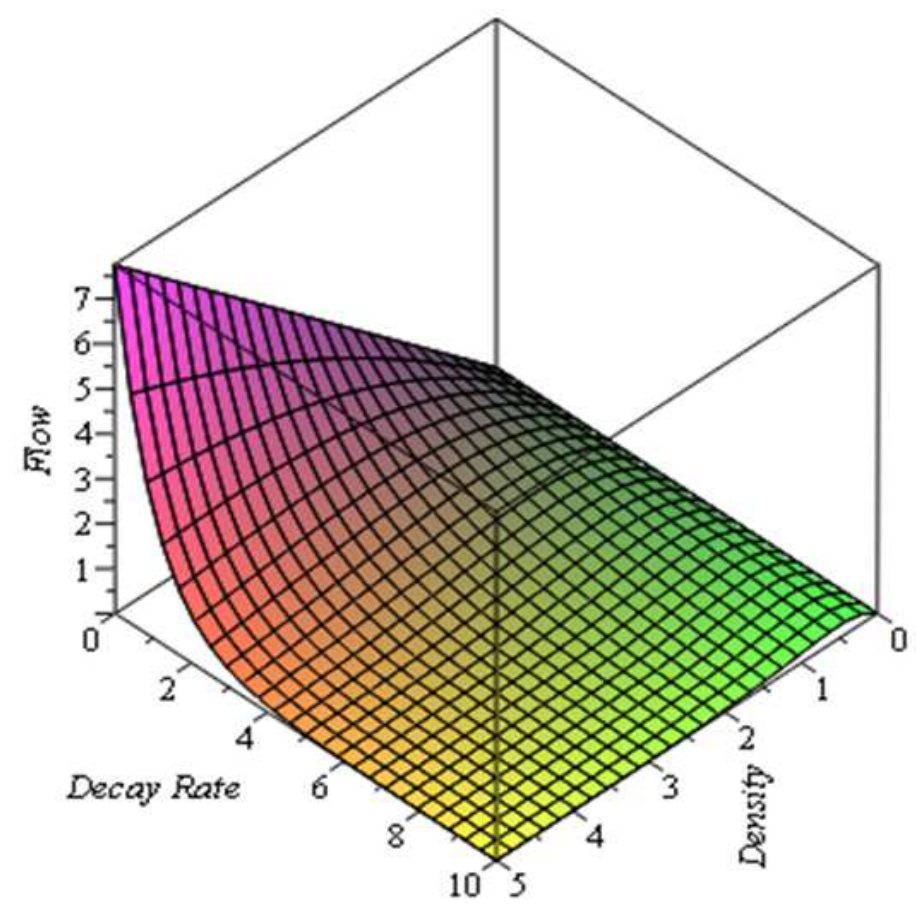

Fig. 4. Relationship between flow, decay rate and density

To model the decrease in speed of pedestrians for an increase in density, the parameter $C_{d}>0$ is introduced in this model which represents the decay rate of speed for an increase in standardized density. The free flow speed $\left(v^{f}\right)$ and the decay rate of speed $\left(C_{d}\right)$ can easily be estimated by the least squares method.

Figure 2 presents the flow-density relationship for the proposed model, Equation 4. It shows that the maximum flow occurs at $k^{C r}, 0<k^{C r}<k_{j}$. In other words, $k^{C r}$ is the critical density that gives the maximum flow. Also at jam density, $k_{j}$, the flow does not drop to zero since pedestrians are able to manage a forward movement at high densities, hence, their speed cannot be zero (Castle, 2007).

As shown in Fig. 2, there is still some flow at jam density $k_{i}$, which is much lower than the maximum flow. In contrast, the flow-density relationships for the Underwood and Drake models (Fig. 1) show that at $k_{j}$, the flow is at its maximum level.

Figure 3 shows the speed-density relationship for different values of $C_{d}$. It shows that for $C_{d}=0$, the relationship is a straight line at $v=v^{f}$. As the value of $C_{d}$ increases, the curve approaches to a nonlinear pattern.

Figure 4 shows the relationship between flow and density for different values of $C_{d}$. As the value of $C_{d}$ increases the curve starts to skew positively, that is the critical density decreases for an increase in $C_{d}$.

\section{Data}

In this research, both primary and secondary data are used to verify the validity of the improved speed-density relationship model. Data are described in details in the next two subsections.

\section{Primary Data}

The primary data is collected from the DTSP hall room of Universiti Sains Malaysia. Figure 5 presents the simplified graphical representation of the internal set up of the hall room. The numbers, $1,2, \ldots, 15$, represent the walkways and the alphabets $S, T, U, V, W, X, Y$ and $Z$ represent the different seating areas.

Data collection surveys have been undertaken during the convocation from the 21st to 25th September 2011 using a photographic procedure. There are two sessions in each day and data for the walkways are collected at the end of each session when the graduates and their guests are exiting the hall room. Three test stretches on three different walkways inside the hall room are selected for data collection. Three video cameras are placed on fixed positions on the top floor by tripods to record the pedestrian movements on the selected test stretches inside the hall room. The widths of the test stretches are fixed throughout the observed length for a set of data. The pedestrian flows are unidirectional and are of varying densities. The recording is done in such a way that pedestrian natural movements are not affected by the presence of the recording instruments or by anything outside the test stretches. The dimensions of widths and lengths for the three chosen test stretches are presented in Table 1. 
Luthful Alahi Kawsar et al. / American Journal of Applied Sciences 2017, 14 (1): 184.203 DOI: 10.3844/ajassp.2017.184.203

Table 1. Dimensions of widths and lengths for the observed test stretches

\begin{tabular}{llc}
\hline Test stretch & Width (in meter) & Length (in meter) \\
\hline Test Stretch 1 (Walkway 8) & 2.0 & 10.1 \\
Test Stretch 2 (Walkway 12) & 1.2 & 18.0 \\
Test Stretch 3 (Walkway 13) & 1.2 & 9.0 \\
\hline
\end{tabular}

Table 2. Description of secondary datasets

\begin{tabular}{lll}
\hline Dataset & Place of research & Flow direction \\
\hline Dataset 1 (Hankin and Wright, 1958) & British Boys' School & Unidirectional \\
Dataset 2 (Mōri and Tsukaguchi, 1987) & Footpaths at downtown Osaka City, Japan. & Unidirectional \\
Dataset 3 (Navin and Wheeler, 1969) & Sidewalks at the University of Missouri (Width: 2.44 m). & Bidirectional \\
Dataset 4 (Oeding, 1963) & Shopping Streets & Bidirectional \\
Dataset 5 (Oeding, 1963) & Mixed Work Traffic & Unidirectional \\
Dataset 6 (Oeding, 1963) & Event Traffic. & Bidirectional \\
Dataset 7 (Older, 1968) & Oxford Street, London (width: 2.29 m) & Bidirectional \\
Dataset 8 (Older, 1968) & Oxford Street, London (width: 3.75 m) & Bidirectional \\
\hline
\end{tabular}

Table 3. ANOVA table

\begin{tabular}{lccccc}
\hline Source of variation & Sum of squares & Df & Mean square & F & p-value \\
\hline Regression & 31.766 & 1 & 31.766 & 745.569 & 0.000 \\
Residual & 4.814 & 113 & 0.043 & & \\
Total & 36.580 & 114 & & & \\
\hline
\end{tabular}

Table 4. Estimated values of $v^{f}, C_{d}$ and test statistic values to test the significance

\begin{tabular}{lllll}
\hline Parameter & Estimated value & t-statistic & p-value & $R^{2}$ \\
\hline$v^{f}$ & 1.550 & 11.655 & 0.000 & 0.87 \\
$C_{d}$ & 2.247 & -27.305 & 0.000 & \\
\hline
\end{tabular}

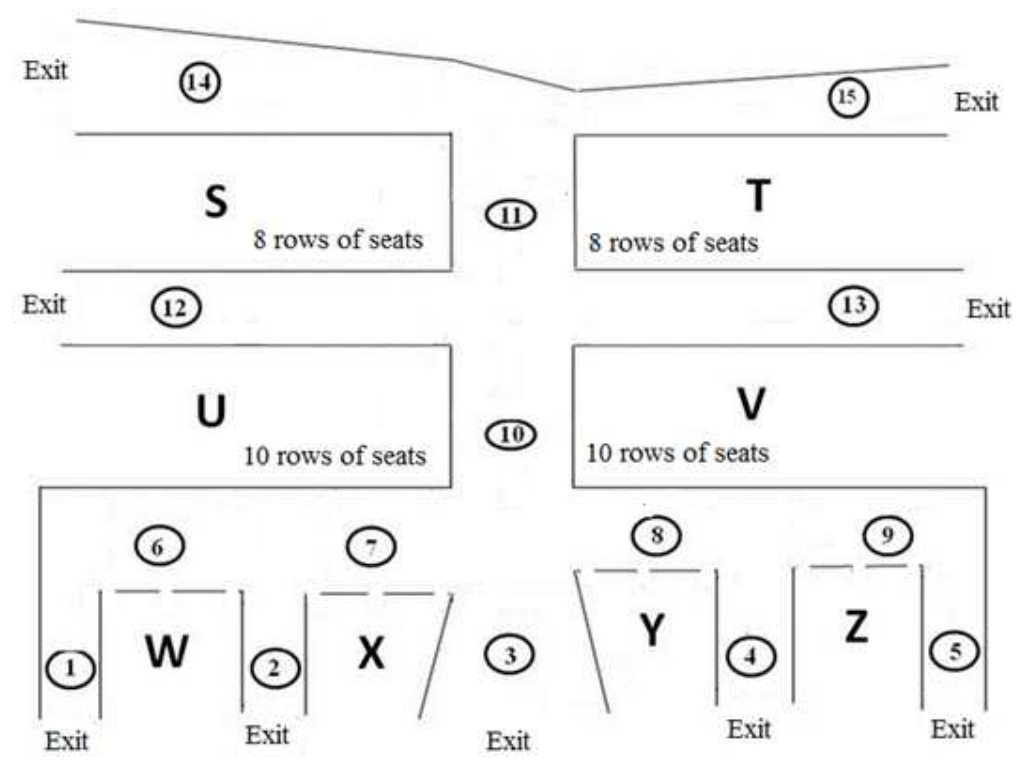

Fig. 5. Simplified representation of walkways of facility

The data are extracted by playing the recorded video files using Adobe Premiere Pro software. The detail procedure of data extraction can be found in the study conducted by Kawsar et al., (2014). In total, a sample of 115 pedestrians from the three chosen test stretches are used for data extraction. From this sample the walking speed and pedestrian density are calculated.

\section{Secondary Data}

Secondary pedestrian speed-density data are available online (Pedestrian data: http://www.ped- 
net.org/index.php?id=20\&ID=213). A complete description of these datasets is presented in Table 2 .

\section{Empirical Validation of the Model}

\section{Primary Data}

\section{Parameter Estimation}

In order to estimate the parameters using a linear regression, Equation 4 is converted to a linear equation by using a logarithmic transformation, that is:

$$
\ln v=\ln v^{f}-C_{d} \cdot \tilde{k}
$$

The least squares method is applied to estimate the two parameters $v^{f}$ and $C_{d}$. Table 3 shows the ANOVA table to test the significance of the model, Equation 5. It shows that there is a significant linear relationship between the variables. The estimates of the parameters along with the tstatistic, p-value and $R^{2}$ are presented in Table 4 .

The value of coefficient of determination, $R^{2}$, is 0.87 , indicating that about $87 \%$ of the variation in walking speed is explained by crowd density. Thus, the regression equation seems to be appropriate for making predictions. At 5\% level of significance, it may be concluded that the slope of the population regression line is significantly different from zero and hence, the density is useful as a predictor of walking speed of pedestrian.

The estimated value of the free flow walking speed, $v^{f}$, is $1.55 \mathrm{~m} \mathrm{sec}^{-1}$. Free flow walking speed reflects the desired speed of a pedestrian that he or she can maintain without getting obstructed by other people encircling him or her (Daamen and Hoogendoorn, 2007). Many studies that estimated the free flow speeds found in the literature are based on pedestrian characteristics and external conditions. Weidmann (1993) has reviewed the available studies on free flow speed and observed a mean free flow speed of $1.34 \mathrm{~m} \mathrm{sec}^{-1}$ and varying from 0.97 to $1.65 \mathrm{~m} \mathrm{sec}^{-1}$. According to Daamen and Hoogendoorn (2006), a direct assessment of free flow speed in a normal setting is not accurate because the pedestrians may not walk with his or her free flow speed. As a result, the free flow speed computed from the observed data is actually underestimated. Based on the data derived from laboratory experiments, Daamen and Hoogendoorn (2007) have estimated the free flow speed for the unidirectional and opposite-directional flows as 1.54 and $1.41 \mathrm{~m} \mathrm{sec}^{-1}$, respectively. The estimated value of free flow speed (Table 4) agrees with the findings of Weidmann (1993) and Daamen and Hoogendoorn (2007). Figure 6 presents the observed speed-density relationship along with the fitted line.

\section{Residual Analysis}

To verify the assumption of the regression analysis, unstandardized residuals and standardized residuals of the transformed model, Equation 5 are plotted against the standardized density, which are presented in Fig. 7 and 8 , respectively. Figure 9 presents a normal probability plot to check the normality of the data.

In statistics, a standardized residual is the quotient resulting from the division of a residual by an estimate of its standard deviation.

The residual plots, Fig. 7 and 8, show that the points are randomly scattered with a constant variance. There are no values beyond the \pm 3 standard deviation reference lines in Fig. 8 which indicates that there are no outliers in the data. The normal probability plot (Fig. 9) of the residuals shows that the points are approximately normally distributed and thus satisfies the assumptions for regression analysis.

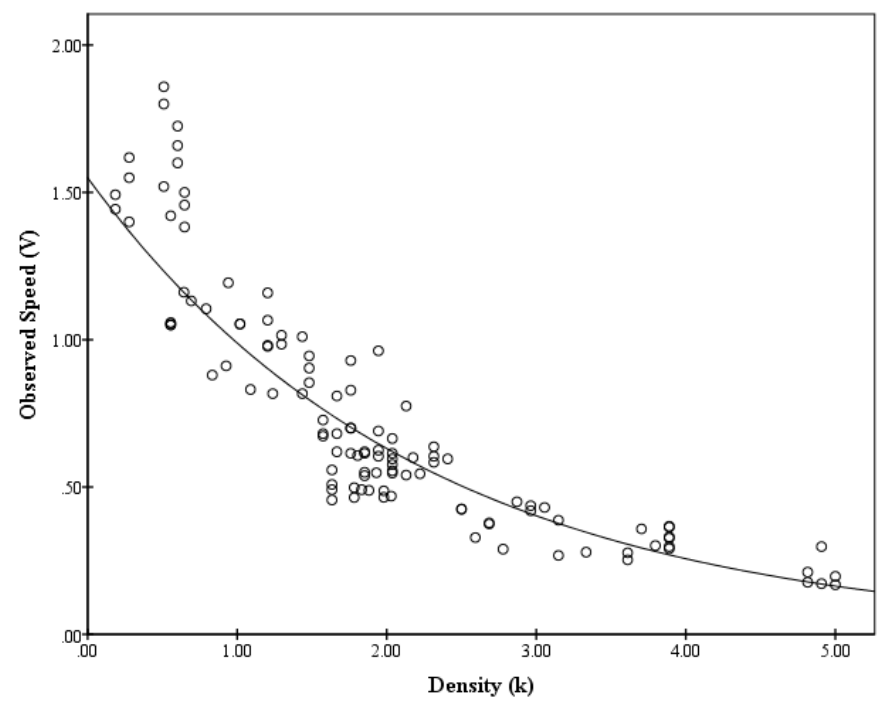

Fig. 6. Observed and estimated speed-density relationships for DTSP data 


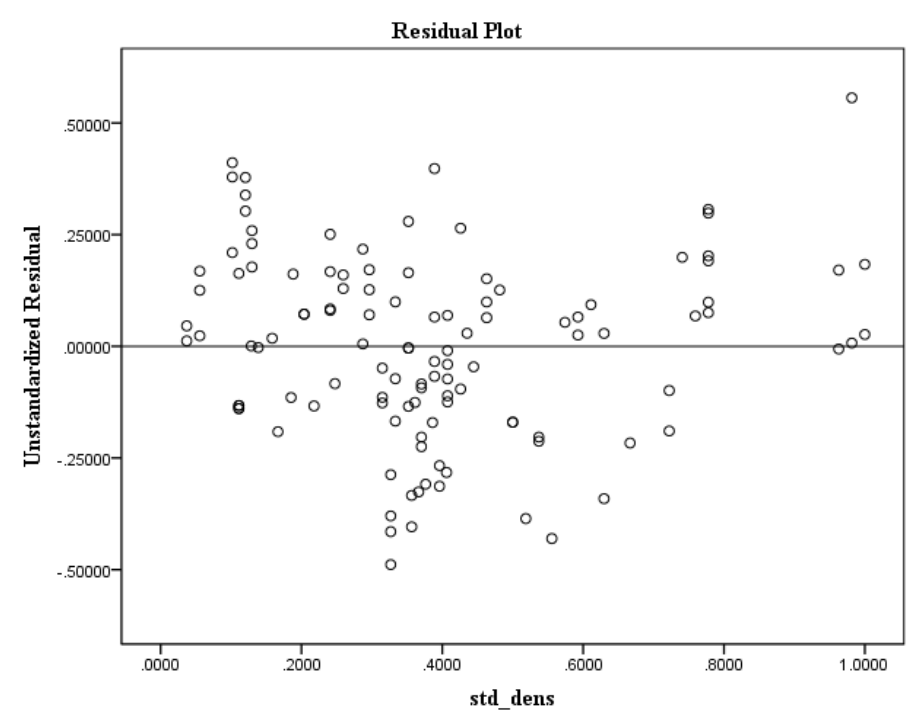

Fig. 7. Unstandardized residuals

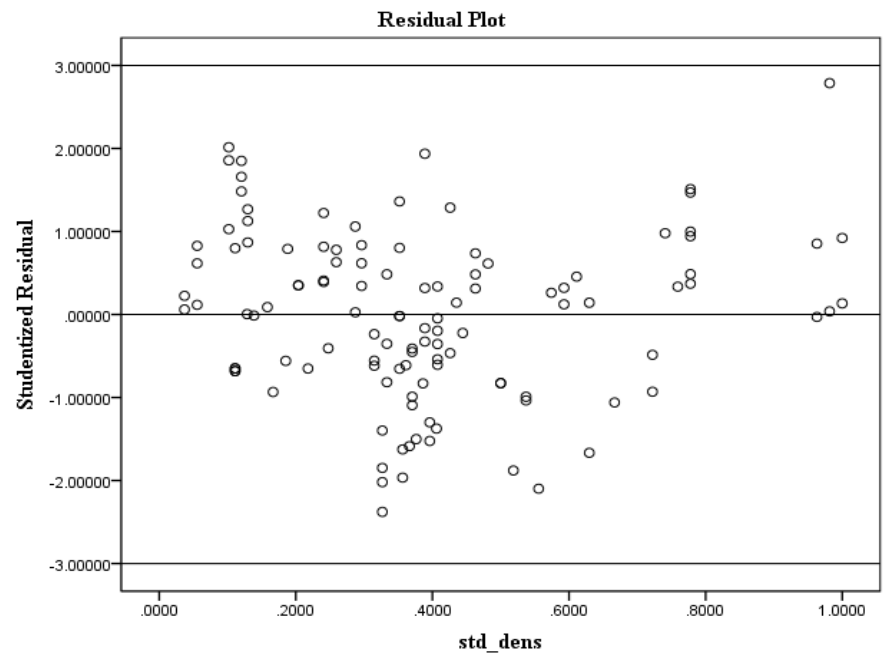

Fig. 8. Standardized residuals

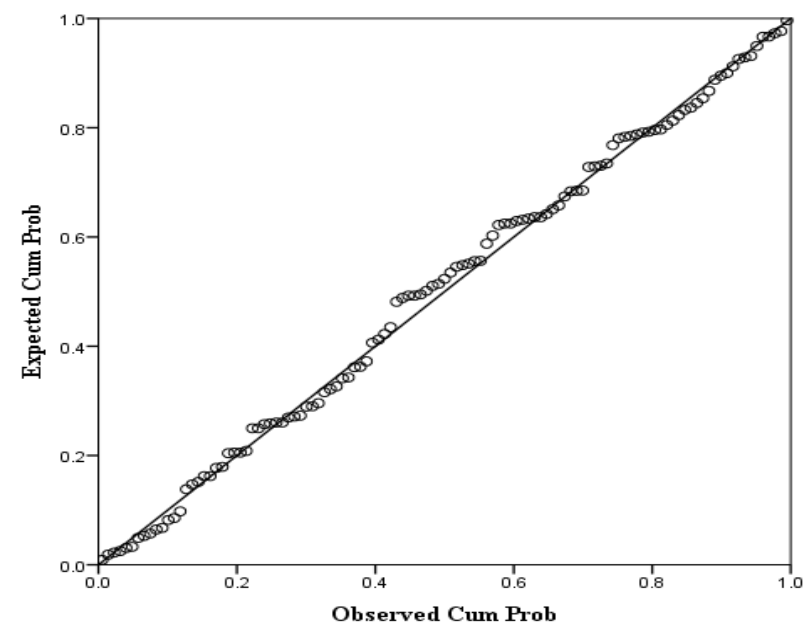

Fig. 9. Normal probability plot 


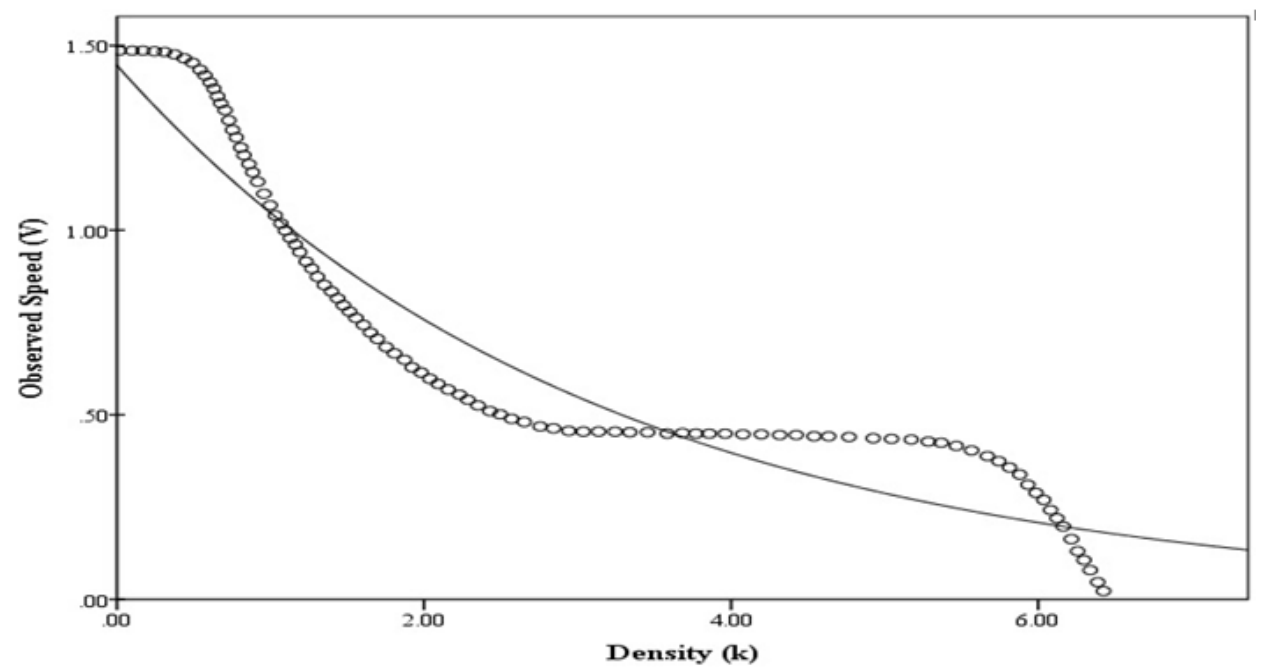

(a)

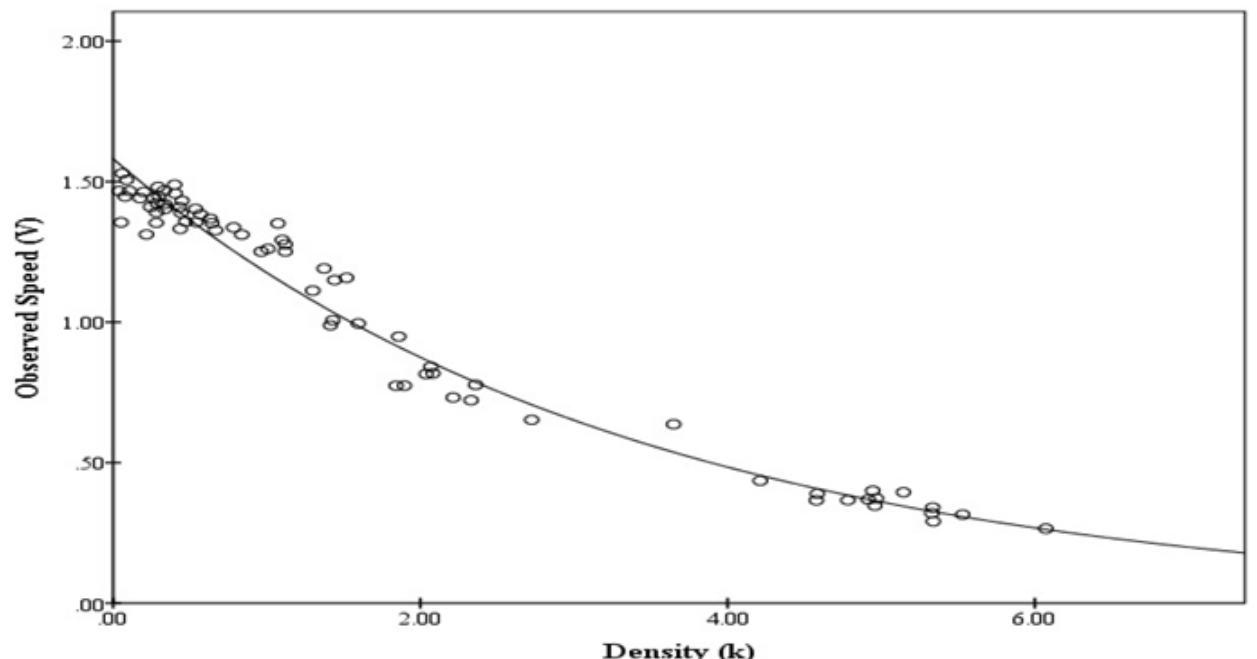

(b)

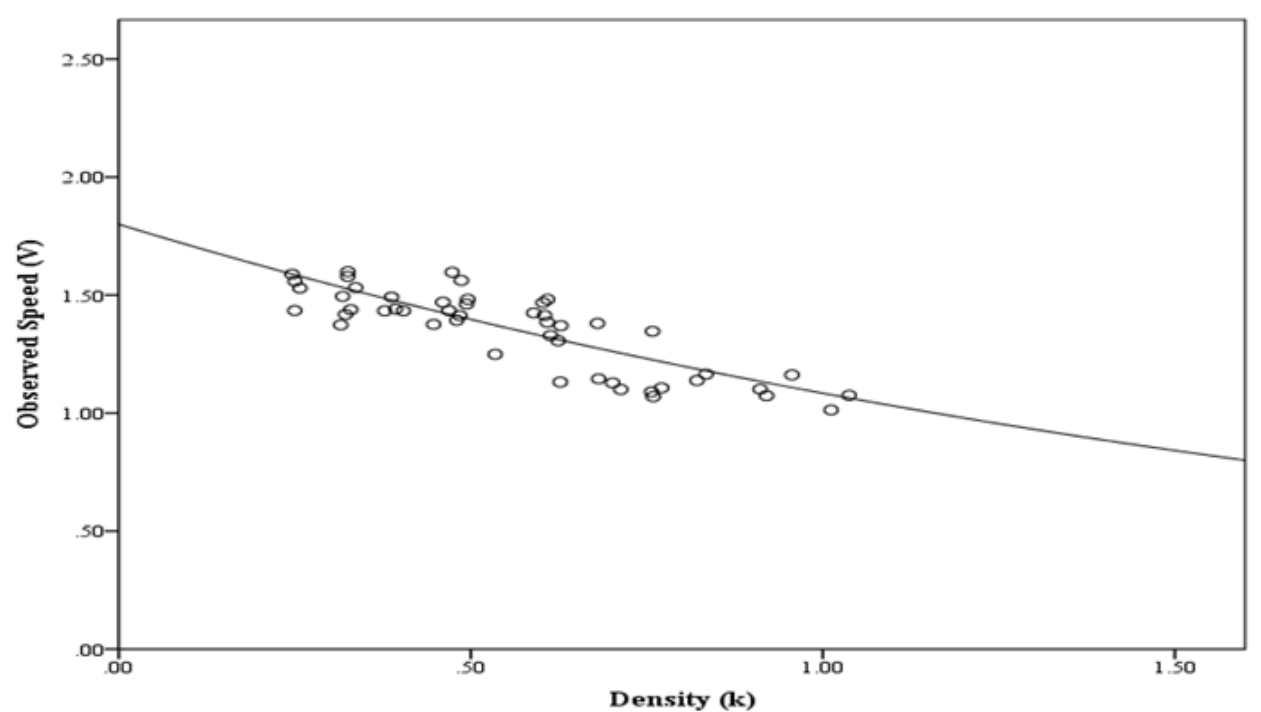

(c) 


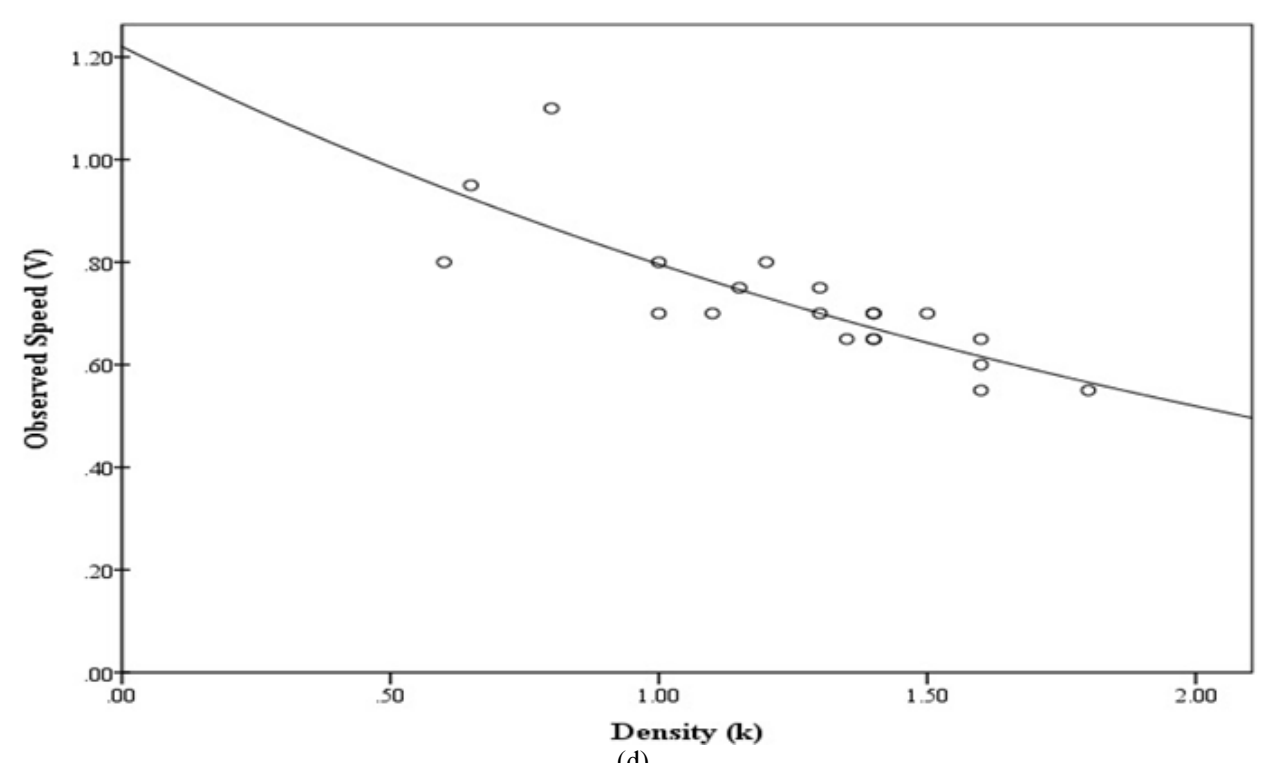

(d)

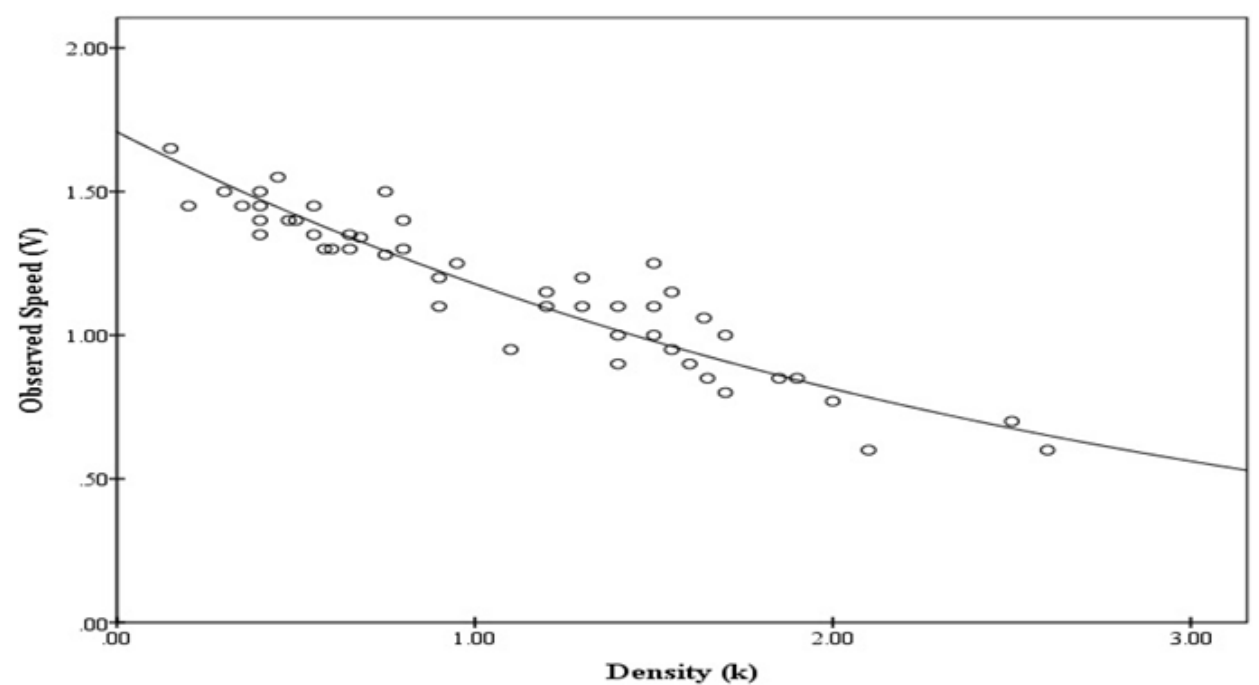

(e)

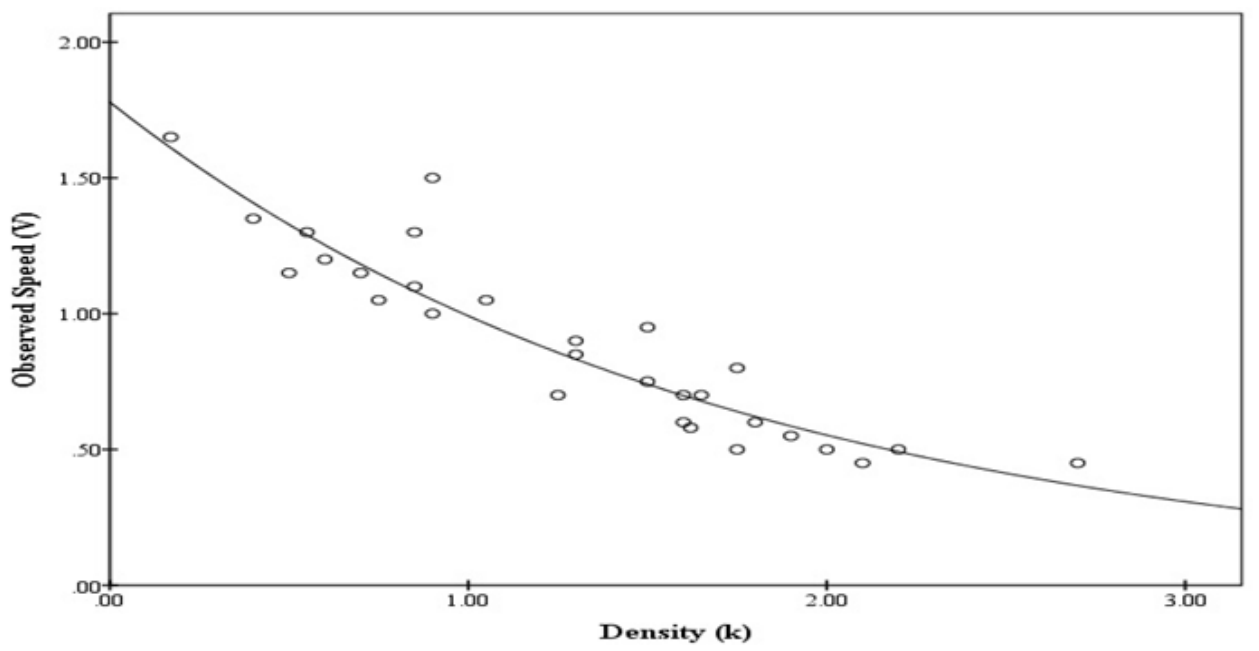

(f) 


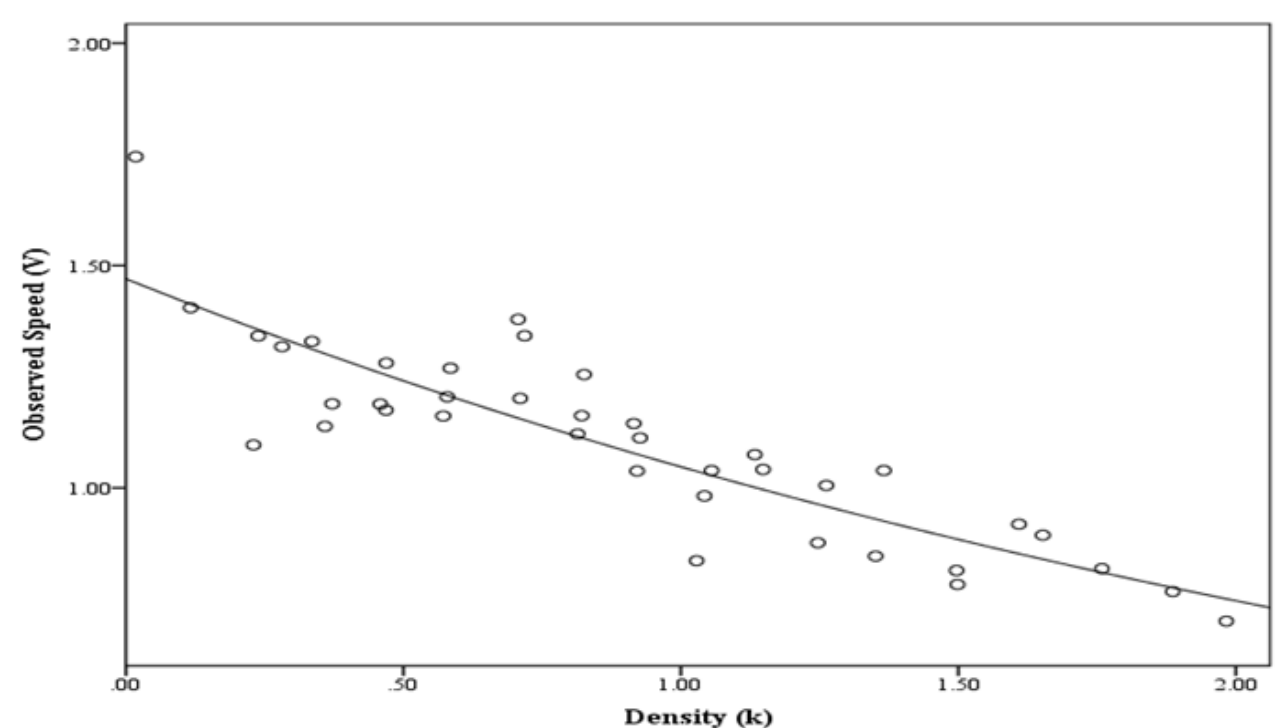

(g)

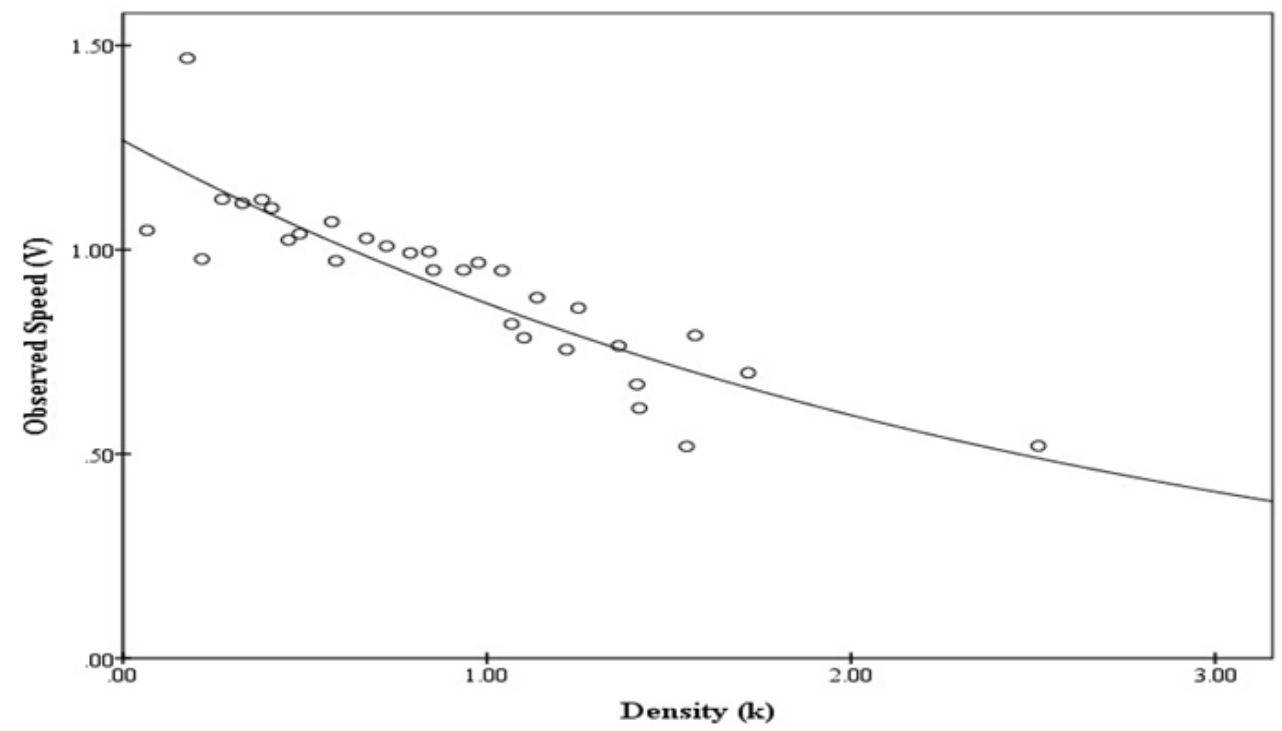

(h)

Fig. 10. (a) Dataset 1 (British Boys' School) (b) Dataset 2 (Footpaths at downtown Osaka City, Japan) (c) Dataset 3 (Sidewalks at the University of Missouri, Width: 2.44 m) (d) Dataset 4 (Shopping Streets) (e) Dataset 5 (Mixed work Traffic) (f) Dataset 6 (Event Traffic) (g) Dataset 7 (Oxford Street, London, Width: $2.29 \mathrm{~m}$ ) (h) Dataset 8 (Oxford Street, London, Width: $3.75 \mathrm{~m}$ )

Table 5. Estimated free flow speed and estimated decay rate of speed and $\mathrm{R}^{2}$ for secondary datasets

\begin{tabular}{llll}
\hline Dataset & Estimated value of $v^{f}$ & Estimated value of $C_{d}$ & $R^{2}$ \\
\hline Dataset 1 & $1.45^{*}$ & $2.085^{*}$ & 0.78 \\
Dataset 2 & $1.58^{*}$ & $1.796^{*}$ & 0.98 \\
Dataset 3 & $1.80^{*}$ & $0.548^{*}$ & 0.72 \\
Dataset 4 & $1.22^{*}$ & $0.769^{*}$ & 0.70 \\
Dataset 5 & $1.71^{*}$ & $0.964^{*}$ & 0.86 \\
Dataset 6 & $1.78^{*}$ & $1.578^{*}$ & 0.87 \\
Dataset 7 & $1.47^{*}$ & $0.678^{*}$ & 0.79 \\
Dataset 8 & $1.27^{*}$ & $0.951^{*}$ & 0.79 \\
\hline
\end{tabular}

*significant at $1 \%$ level of significance 


\section{Secondary Data}

To verify the validity of the proposed model, it has also been fitted to the secondary pedestrian speeddensity data that are available online (Pedestrian data: http://www.ped-net.org/index.php?id=20\&ID=213).

\section{Parameter Estimation}

The estimated values of the parameters $v^{f}$ and $C_{d}$ for all the datasets along with $R^{2}$ statistics are presented in Table 5 . For all the datasets, the values of $C_{d}$ are positive, showing the decreasing relationship between pedestrian speed and density. The values of $R^{2}$ statistic for all the datasets show that the model can adequately describe the data that are collected from different scenarios. The observed and estimated values of speed against density for all the datasets are presented in Fig. 10a to $10 \mathrm{~h}$.

\section{Residual Analysis}

To verify the assumption of the regression analysis, unstandardized residuals and studentized residuals of the transformed model, Equation 5, are plotted against the standardized density for all the secondary datasets. Normal probability plot is used to check the normality of all the datasets. The residual plots and the normal probability plots for all the datasets are given in Appendix. The residual plots for all the secondary datasets show that there are no outliers in the data. The normal probability plots of the residuals for all the secondary datasets show that the residuals are approximately normally distributed. Thus, the assumptions for regression analysis are satisfied.

\section{Conclusion}

The relationship between pedestrians' walking speed and density is important in the study of the evacuation of facilities, as it is directly related with the capability of a walkway to maintain a preferred pedestrian flow along its length. In this study, an improved speed-density relationship model is proposed for pedestrian flow that shows a maximum flow at a density, which is less than jam density and thus, overcome the limitations of the Underwood and Drake Models. The validity of the model has been verified by fitting it to a primary dataset and eight different secondary datasets using regression analysis. The results show that the developed model can describe the speed-density relationship for all the datasets that are collected from the different scenarios such as the indoor and outdoor facilities.

\section{Acknowledgement}

This material is based upon work supported by the Hajj Research Cluster, USM No. 203.PTS.6720008.

\section{Author's Contributions}

All the authors contributed equally to prepare, develop and carry out this manuscript.

\section{Ethics}

This article is original and contains unpublished material. The authors confirm that there are no ethical issues involved.

\section{References}

Al-Azzawi, M. and R. Raeside, 2007. Modeling pedestrian walking speeds on sidewalks. J. Urban Plann. Dev., 133: 211-219.

DOI: 10.1061/(ASCE)0733-9488(2007)133:3(211

Alhajyaseen, W.K. and H. Nakamura, 2010. Quality of pedestrian flow and crosswalk width at signalized intersections. IATSS Res., 34: 35-41.

DOI: $10.1016 /$ j.iatssr.2010.06.002

Alhajyaseen, W.K., H. Nakamura and M. Asano, 2011. Effects of bi-directional pedestrian flow characteristics upon the capacity of signalized crosswalks. Proc. Soc. Behav. Sci., 16: 526-535. DOI: 10.1016/j.sbspro.2011.04.473

Burns, R.D.I. and P.S. Lykoudis, 1973. Characteristics of pedestrian traffic: Center of applied stochastics. Purdue University.

Castle, C.J., 2007. Guidelines for assessing pedestrian evacuation software applications. UCL Working Paper Series, Centre for Advanced Spatial Analysis.

Chattaraj, U., A. Seyfried and P. Chakroborty, 2009. Comparison of pedestrian fundamental diagram across cultures. Adv. Complex Syst., 12: 393-405. DOI: $10.1142 / \mathrm{S} 0219525909002209$

Daamen, W. and S.P. Hoogendoorn, 2006. Free speed distributions for pedestrian traffic. Paper read at TRB-Annual Meeting, Washington.

Daamen, W. and S.P. Hoogendoorn, 2007. Free Speed Distributions-Based on Empirical Data in Different Traffic Conditions. In: Pedestrian and Evacuation Dynamics 2005, Waldau, N., P. Gattermann, H. Knoflacher and M. Schreckenberg (Eds.), Springer Berlin Heidelberg, ISBN-10: 3540470646, pp: 13-25.

Drake, J., J. Schofer and A. May, 1967. A statistical analysis of speed-density hypotheses in vehicular traffic science. Proceedings of the 3rd International Symposium on the Theory of Traffic Flow, (TTF' 67), Highway Research Board, pp: 112-117.

Drew, D.R., 1968. Traffic Flow Theory and Control. 1st Edn., McGraw-Hill, New York, pp: 467.

Fang, Z., S. Lo and J. Lu, 2003. On the relationship between crowd density and movement velocity. Fire Safety J., 38: 271-283.

DOI: $10.1016 / \mathrm{S} 0379-7112(02) 00058-9$ 
Fruin, J.J., 1971a. Pedestrian Planning and Design. 1st Edn., Metropolitan Association of Urban Designers and Environmental Planners, New York, pp: 206.

Fruin, J.J., 1971b. Designing for Pedestrians: A Level-ofService Concept. 1st Edn., Highway Research Record.

Greenberg, H., 1959. An analysis of traffic flow. Operat. Res., 7: 79-85. DOI: 10.1287/opre.7.1.79

Greenshields, B.D., J. Bibbins, W. Channing and H. Miller, 1935. A study of traffic capacity. Paper read at Highway Research Board Proceedings, Washington D.C.

Gupta, A. and N. Pundir, 2015. Pedestrian flow characteristics studies: A review. Transport Rev., 35: 445-465. DOI: 10.1080/01441647.2015.1017866

Hankin, B.D. and R.A. Wright, 1958. Passenger flow in subways. OR, 9: 81-88. DOI: 10.2307/3006732

Henderson, L., 1971. The statistics of crowd fluids. Nature, 229: 381-383. DOI: 10.1038/229381a0

Henderson, L., 1974. On the fluid mechanics of human crowd motion. Transport. Res., 8: 509-515. DOI: 10.1016/0041-1647(74)90027-6

Henderson, L. and D. Jenkins, 1974. Response of pedestrians to traffic challenge. Transport. Res., 8: 71-74. DOI: 10.1016/0041-1647(74)90019-7

Henderson, L. and D. Lyons, 1972. Sexual differences in human crowd motion. Nature, 240: 353-355. DOI: $10.1038 / 240353 \mathrm{a} 0$

HRB, 1965. Highway Capacity Manual. Special Report No. 87, National Research Council, Washington D.C.

Jia, H., L. Yang and M. Tang, 2009. Pedestrian flow characteristics analysis and model parameter calibration in comprehensive transport terminal. J. Transport. Syst. Eng. Inform. Technol., 9: 117-123. DOI: 10.1016/S1570-6672(08)60082-3

Kachroo, P.P., S.J. Al-Nasur, S.A. Wadoo and A. Shende, 2008. Pedestrian Dynamics: Feedback Control of Crowd Evacuation. 1st Edn., Springer, Berlin, ISBN-10: 3540755616, pp: 246.

Kawsar, L.A., N.A. Ghani, A.A. Kamil and A. Mustafa, 2014. Empirical relationships among pedestrian flow characteristics in an indoor facility. Res. J. Applied Sci. Eng. Technol., 8: 952-963. DOI: $10.19026 /$ rjaset.8.1057

Lam, W.H. and C.Y. Cheung, 2000. Pedestrian speed/flow relationships for walking facilities in Hong Kong. J. Transport. Eng., 126: 343-349. DOI: 10.1061/(ASCE)0733-947X(2000)126:4(343)

Lam, W.H., J.F. Morrall and H. Ho, 1995. Pedestrian flow characteristics in Hong Kong. Transport. Res. Record.

Laxman, K.K., R. Rastogi and S. Chandra, 2010. Pedestrian flow characteristics in mixed traffic conditions. J. Urban Plann. Dev., 136: 23-33. DOI: 10.1061/(ASCE)0733-9488(2010)136:1(23)

Lee, Y.C., 2005. Pedestrian walking and choice behavior on stairways and escalators in public transport facilities. TU Delft, Delft University of Technology.
May, A.D., 1990. Traffic Flow Fundamental. 1st Edn., Prentice Hall, New Jersey, pp: 464.

Mōri, M. and H. Tsukaguchi, 1987. A new method for evaluation of level of service in pedestrian facilities. Transport. Res. Part A General, 21: 223-234. DOI: 10.1016/0191-2607(87)90016-1

Morrall, J. F., L. Ratnayake and P. Seneviratne, 1991. Comparison of central business district pedestrian characteristics in Canada and Sri Lanka. Transport. Res. Record.

Navin, F. and R. Wheeler, 1969. Pedestrian flow characteristics. Traffic Eng., Inst. Traffic Eng.

Oeding, D., 1963. Traffic loads and dimensions of walkways and other pedestrian circulation facilities. Straßenbau und Straßenverkehrstechnik.

Older, S.J., 1968. Movement of pedestrians on footways in shopping streets. Traffic Eng. Control, 10: 160-163.

Pipes, L.A., 1967. Car following models and the fundamental diagram of road traffic. Transport. Res., 1: 21-29. DOI: 10.1016/0041-1647(67)90092-5

Predtechenskii, V.M., 1966. Pedestrian Traffic Flow and the Determination of Passage Dimensions in Buildings. In: Achitecture of Public and Industrial Buildings, Stroiizdat, Moscow, pp: 240-240.

Predtechenskii, V.M. and A.I. Milinskii, 1978. Planning for Foot Traffic Flow in Buildings. 1st Edn., Amerind Publishing, New Dehli, ISBN-10: 0862493269, pp: 248.

Pushkarev, B. and J.M. Zupan, 1975. Urban Space for Pedestrians: A Report of the Regional Plan Association. 1st Edn., MIT Press, Cambridge, ISBN-10: 0262160633, pp: 212.

Rahman, K., N.A. Ghani, A.A. Kamil and A. Mustafa, 2012. Analysis of pedestrian free flow walking speed in a least developing country: a factorial design study. Res. J. Applied Sci., 4: 4299-4304.

Rastogi, R., T. Ilango and S. Chandra, 2013. Pedestrian flow characteristics for different pedestrian facilities and situations. Eur. Transport.

Sarkar, A. and K. Janardhan, 2001. Pedestrian flow characteristics at an intermodal transfer terminal in Calcutta. World Transport Policy Pract., 7: 34-40.

Shende, A., P. Kachroo, C. Konda Reddy and M. Singh, 2007. Optimal control of pedestrian evacuation in a corridor. Proceedings of the IEEE Intelligent Transportation Systems Conference, Sept. 30-Oct. 3, IEEE Xplore Press, pp: 385-390.

DOI: $10.1109 /$ ITSC.2007.4357775

Tanaboriboon, Y. and J. Guyano, 1991. Analysis of pedestrian movements in Bangkok. Transport. Res. Record.

Tanaboriboon, Y., S.S. Hwa and C.H. Chor, 1986. Pedestrian characteristics study in Singapore. J. Transport. Eng., 112: 229-235. DOI: 10.1061/(ASCE)0733-947X(1986)112:3(229) 
Tregenza, P., 1976. The Design of Interior Circulation: People and Building. 3rd Edn., Crosby Lockwood Staples, London, ISBN-10: 0258969989, pp: 159.

Underwood, R.T., 1960. Speed, Volume and Density Relationships. In: Bureau of Highway Traffic, Bureau of Highway Traffic, Yale University, Victoria, pp: 141-188.

Virkler, M.R. and S. Elayadath, 1994. Pedestrian speedflow-density relationships. Transportation Research Board.

Wang, H., 2010. Stochastic modeling of the equilibrium speed-density relationship. Dissertation, Civil and Environmental Engineering, University of Massachusetts, Amherst.
Weidmann, U., 1993. Transporttechnik der Fussgänger, Transporttechnische Eigenschaften des Fussgängerverkehrs (Literturaus wertung)[Transport technique of pedestrians, Transportation Technical characteristics of pedestrian traffic (Literture evaluation). The IVT Series No. 90, Zürich.

Yao, L., L. Sun, Z. Zhang, S. Wang and J. Rong, 2012. Research on the behavior characteristics of pedestrian crowd weaving flow in transport terminal. Math. Problems Eng., 2012: 264295-264303. DOI: $10.1155 / 2012 / 264295$

Yuhaski, S.J. and J.M. Smith, 1989. Modeling circulation systems in buildings using state dependent queueing models. Queueing Syst., 4: 319-338. DOI: 10.1007/BF01159471

\section{Appendix}

\section{Dataset 1}

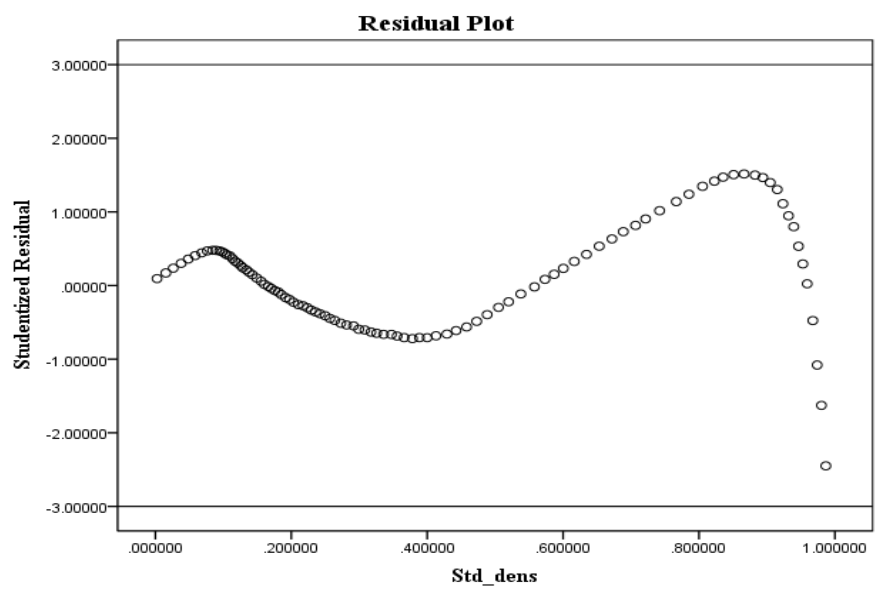

Studentized residuals for dataset 1

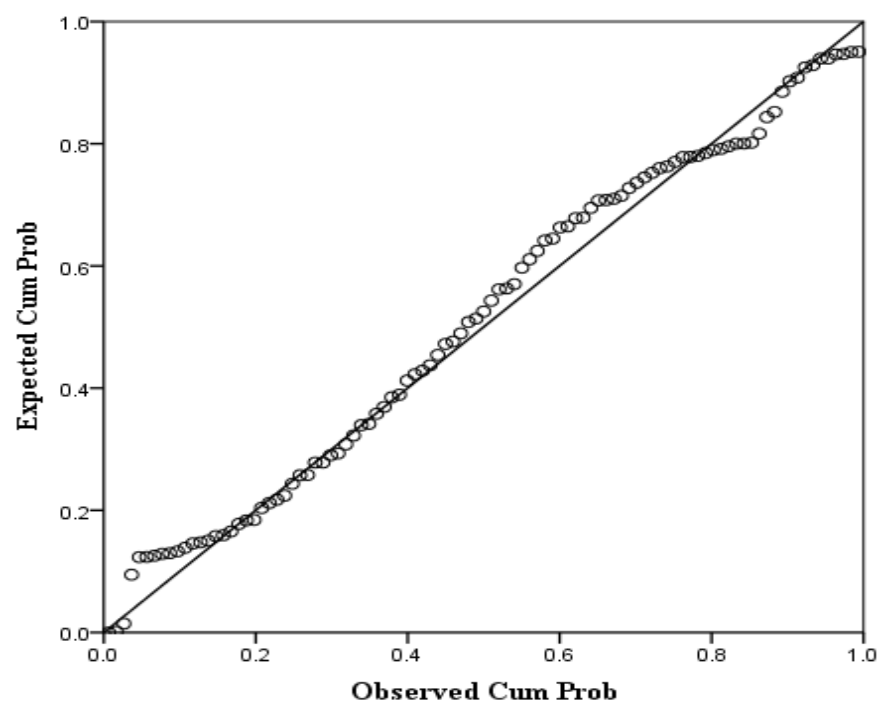

Normal probability plot for dataset 1 


\section{Dataset 2}

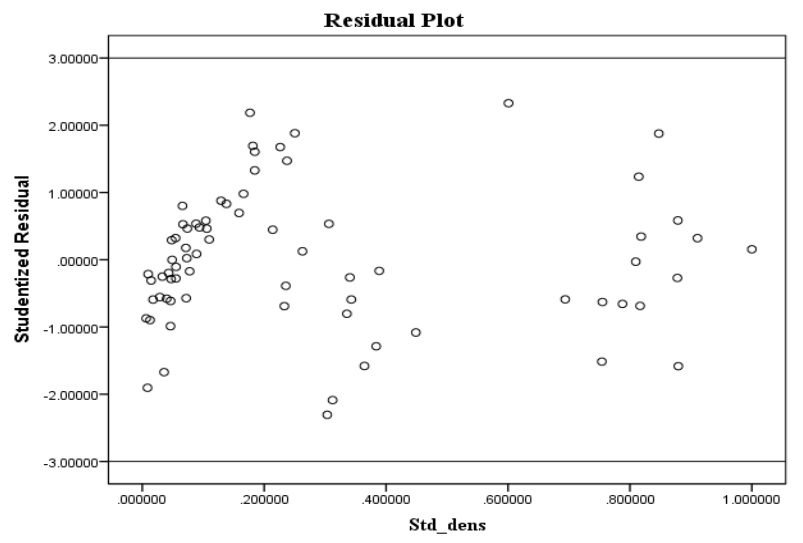

Studentized residuals for dataset 2

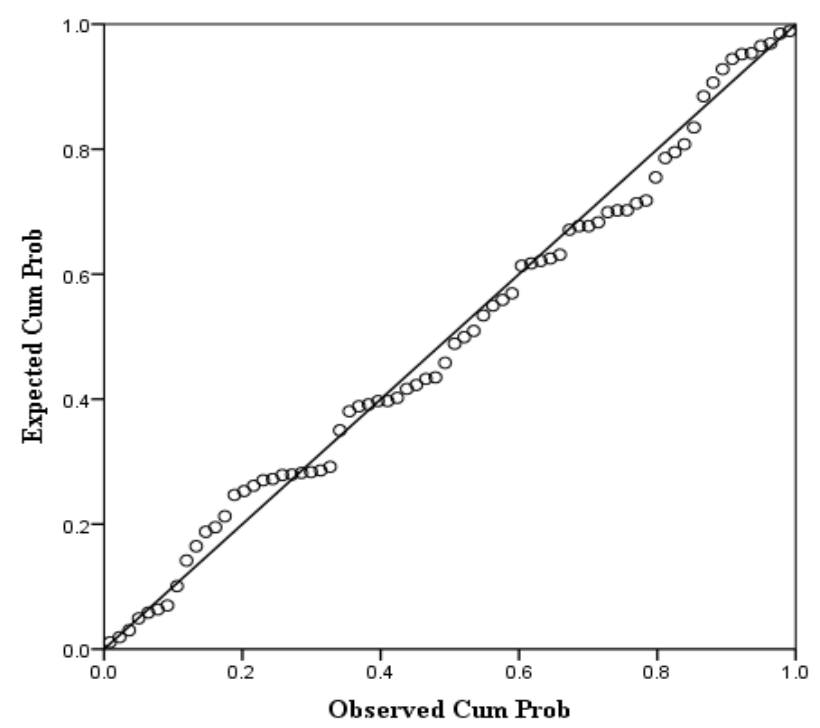

Normal probability plot for dataset 2

\section{Dataset 3}

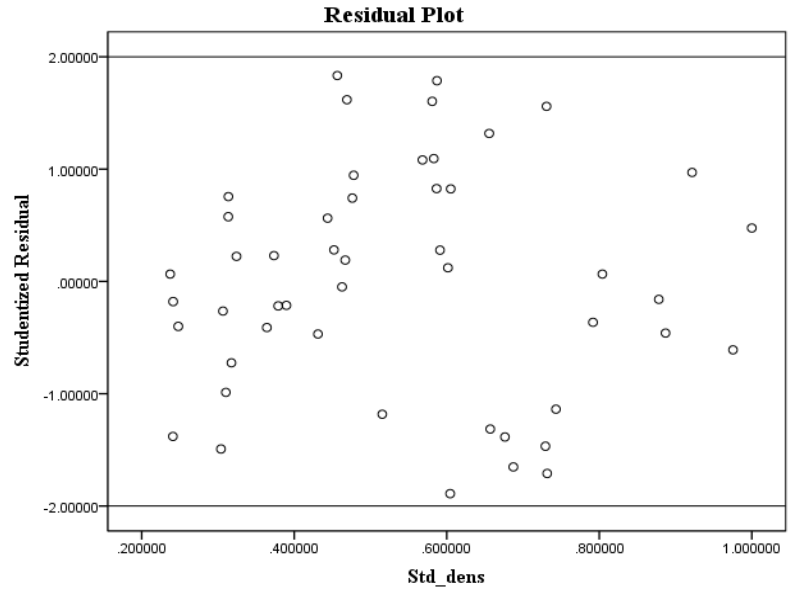

Studentized residuals for dataset 3 


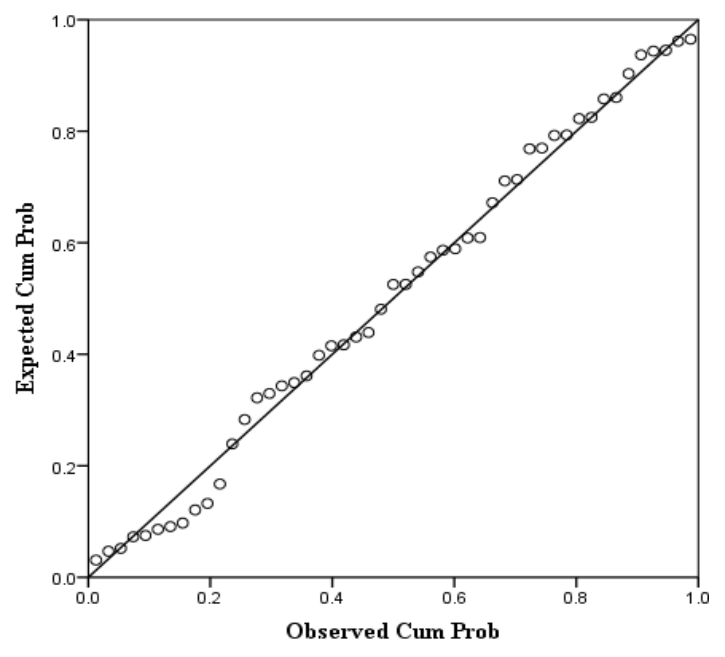

Normal probability plot for dataset 3

\section{Dataset 4}

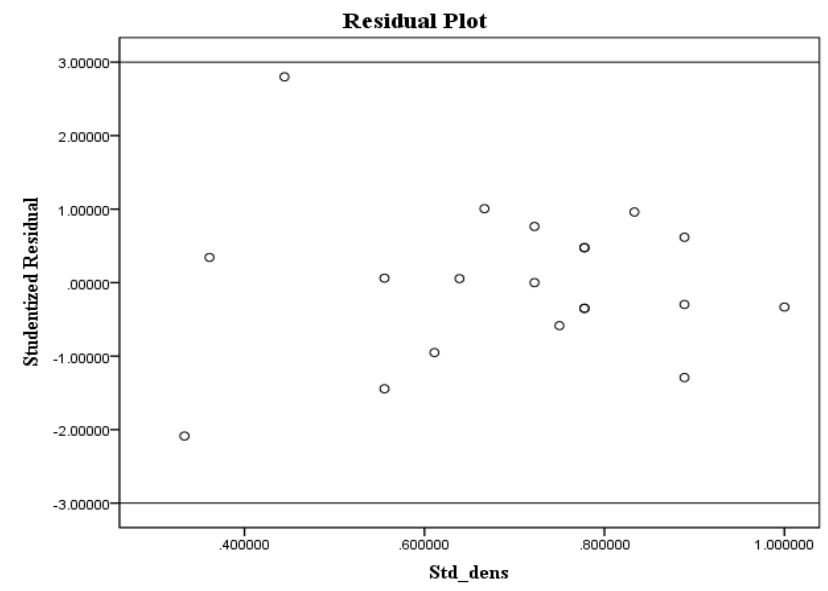

Studentized residuals for dataset 4

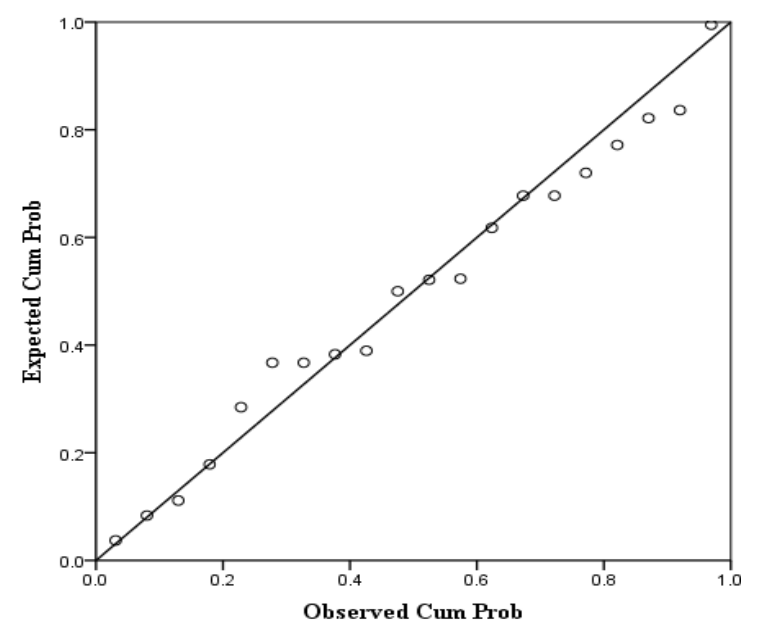

Normal probability plot for dataset 4 


\section{Dataset 5}

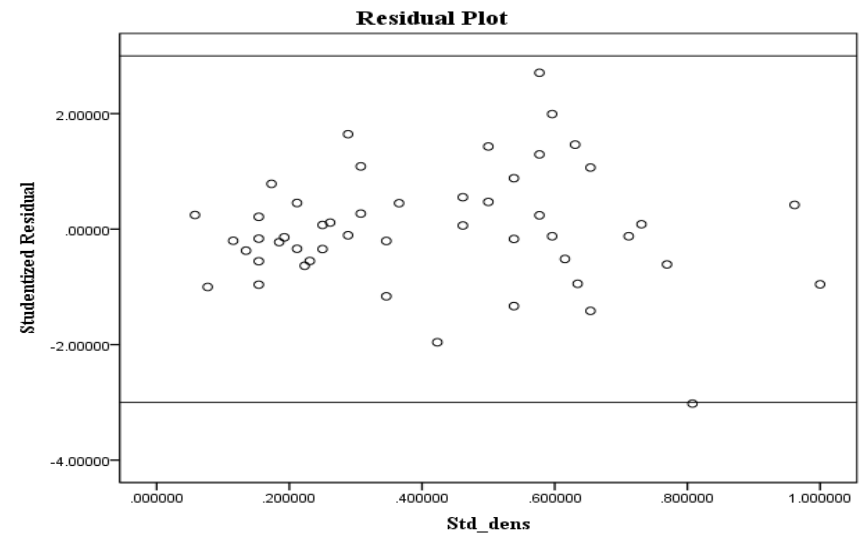

Studentized residuals for dataset 5

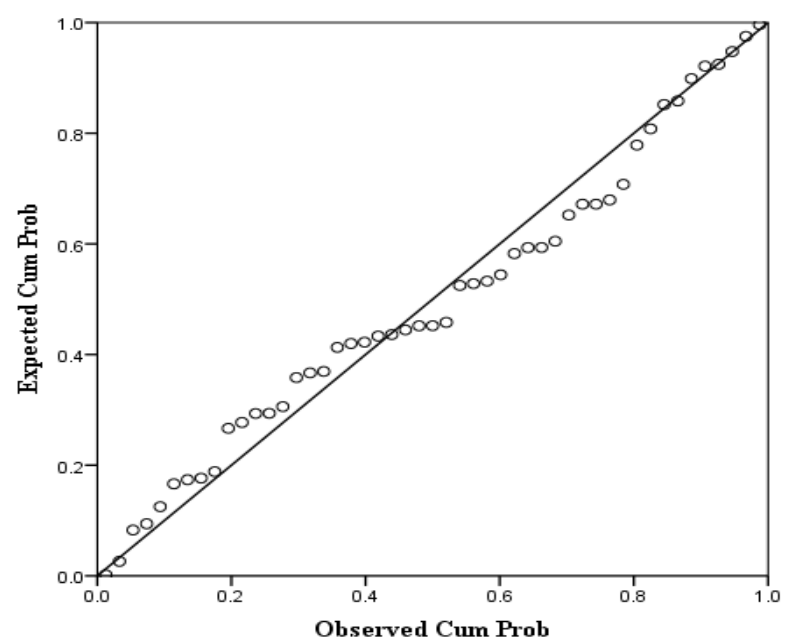

Normal probability plot for dataset 5

\section{Dataset 6}

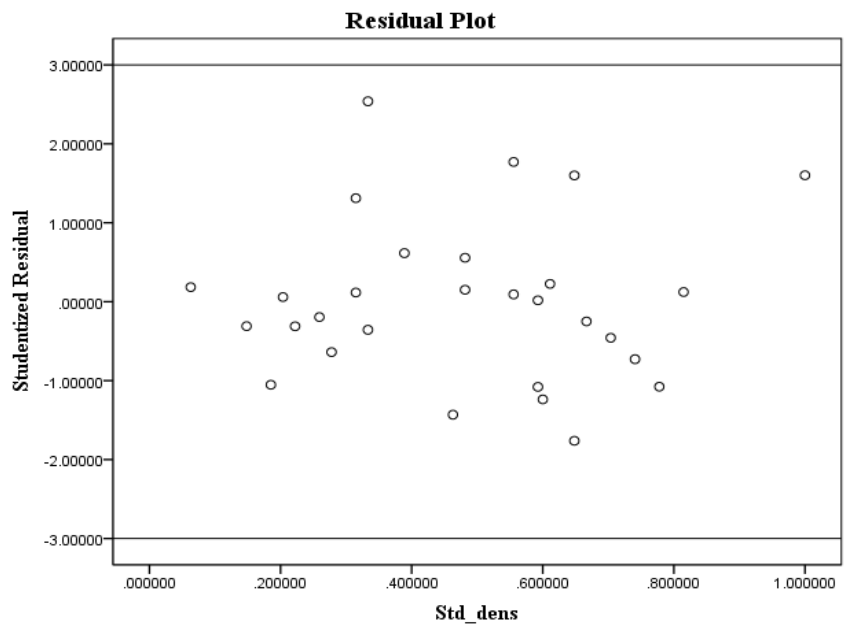

Studentized residuals for dataset 6 


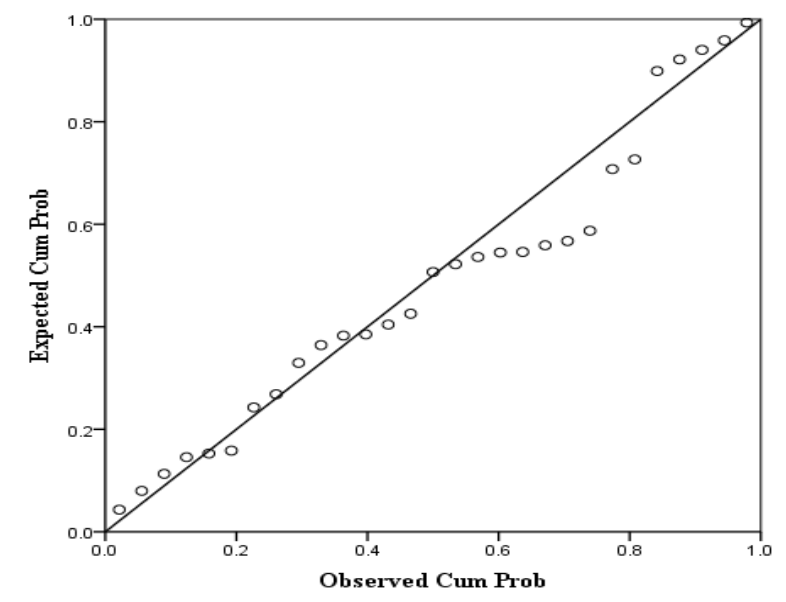

Normal probability plot for dataset 6

\section{Dataset 7}

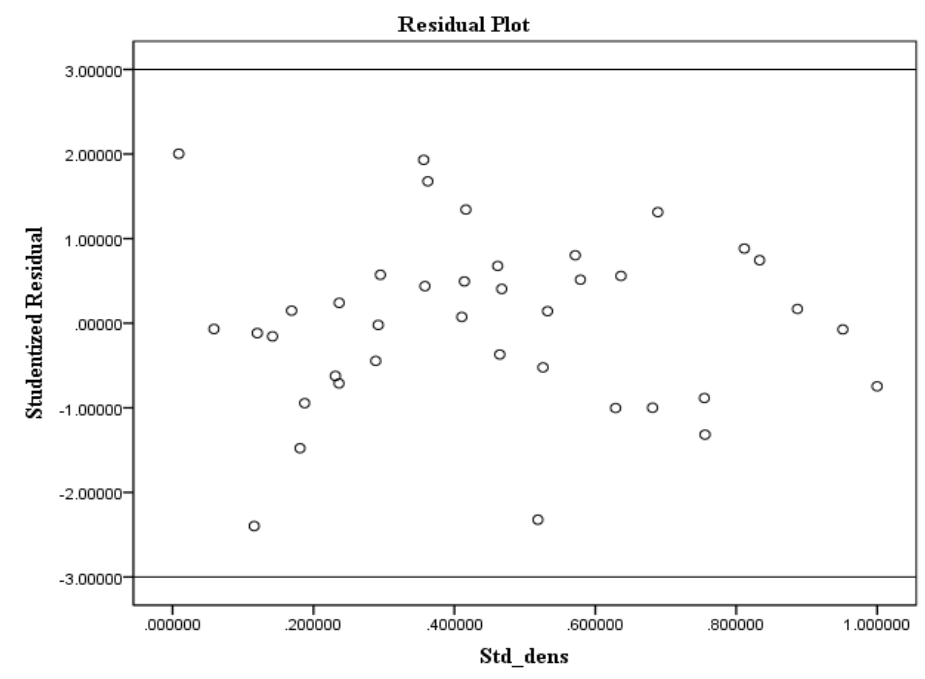

Studentized residuals for dataset 7

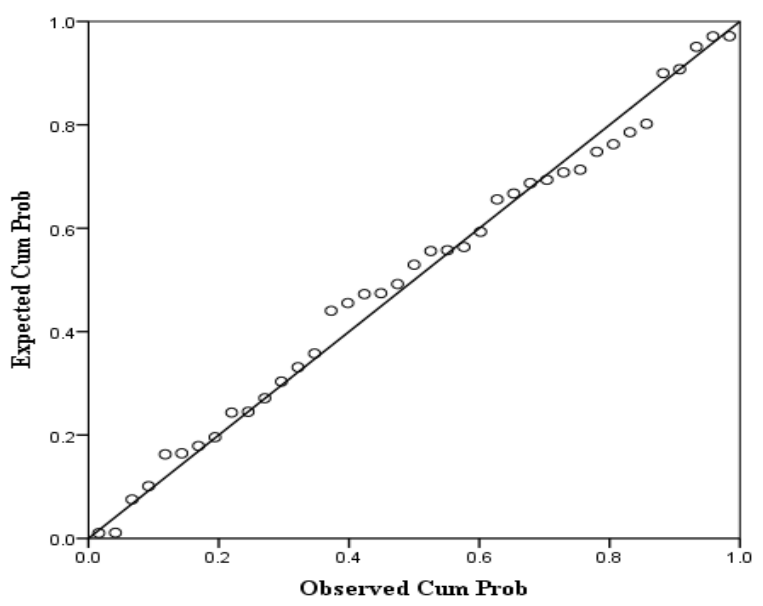

Normal probability plot for dataset 7 


\section{Dataset 8}

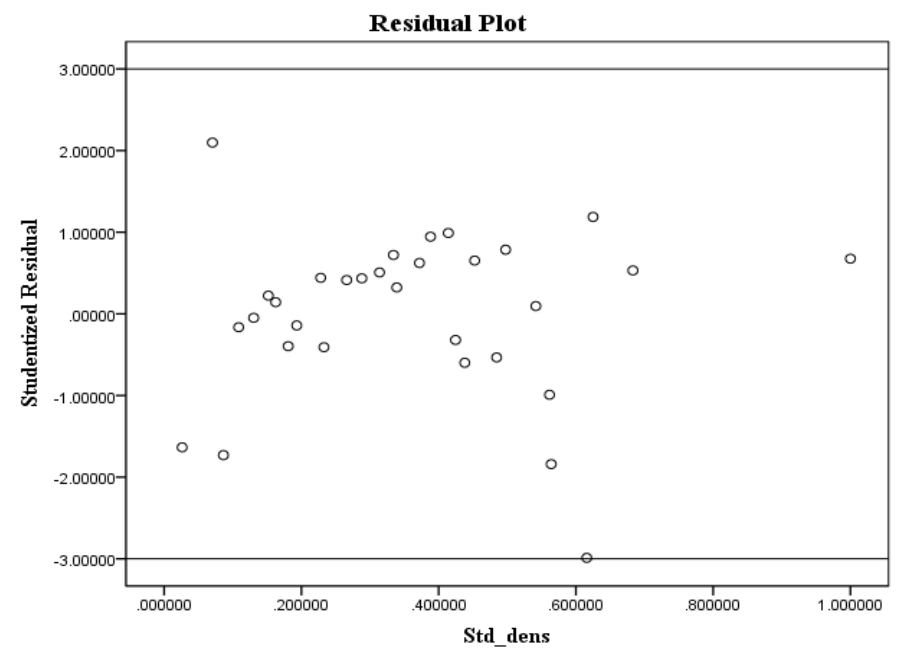

Studentized residuals for dataset 8

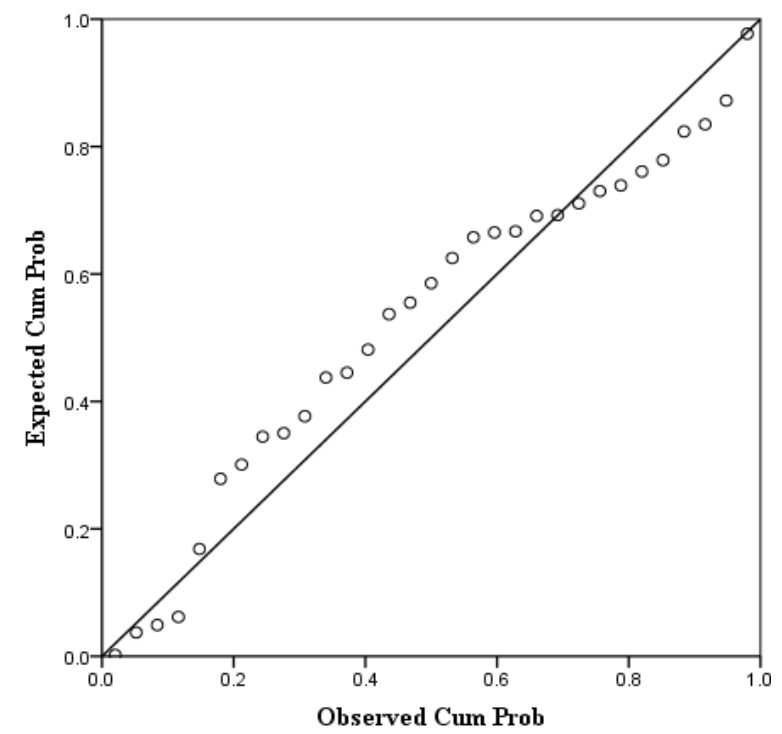

Normal probability plot for dataset 8 